\title{
CONVENTIONAL AND UNCONVENTIONAL APPROACHES TO EXCHANGE RATE MODELLING AND ASSESSMENT
}

\author{
RON ALQUIST ${ }^{\mathrm{a}}{ }^{\dagger}$ and MENZIE D. CHINN ${ }^{\mathrm{b}}$

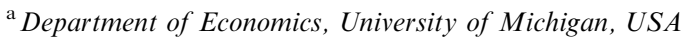 \\ ${ }^{\mathrm{b}}$ Robert M. La Follette School of Public Affairs, and Department of Economics, University of Wisconsin, USA
}

\begin{abstract}
We examine the relative predictive power of the sticky price monetary model, uncovered interest parity, and a transformation of net exports and net foreign assets. In addition to bringing Gourinchas and Rey's new approach and more recent data to bear, we implement the Clark-West procedure for testing the significance of out-of-sample forecasts. The interest rate parity relation holds better at long horizons and the net exports variable does well in predicting exchange rates at short horizons in sample. In out-of-sample forecasts, we find evidence that our proxy for Gourinchas and Rey's measure of external imbalances outperforms a random walk at short horizons as do some of the other models, although no single model uniformly beats the random walk forecast. Copyright (C) 2007 John Wiley \& Sons, Ltd.
\end{abstract}

JEL CODE: F31; F47

KEY WORDS: Exchange rates; net foreign assets; interest rate parity; monetary model; forecasting performance

\section{INTRODUCTION}

Over the last two years, movements in dollar exchange rates have proven as inexplicable as ever. We take up the issue of whether there are enduring instances where economic models can explain and predict future movements in exchange rates. In doing so, we incorporate three innovations into our analysis.

First, we examine the behaviour of several key dollar exchange rates during the first euro-dollar cycle. There is ample interest in the post-1999 behaviour of the euro, particularly its initial depreciation and subsequent sharp appreciation, which provided the basis for previous studies, as in Nautz and Offermans (2006), Heaney and Pattenden (2005), Mussa (2005), Schnatz et al. (2004), and Chinn and Alquist (2000). Second, we examine the relative performance of a model incorporating a role for net foreign assets, as suggested in Gourinchas and Rey's (2005) financial adjustment channel and Lane and Milesi-Ferretti (forthcoming). Third, we employ a new test that is appropriate for evaluating nested models. Standard tests for the statistical significance of out-of-sample forecasts are wrongly sized. ${ }^{1}$

In a recent paper, Gourinchas and Rey suggested that multilateral dollar exchange rates are well predicted by a procedure that takes into account financial adjustment. The channel is the natural implication of an intertemporal budget constraint that allows for valuation changes in foreign assets and liabilities. More broadly, there is a large literature that links foreign assets and liabilities to exchange rates (Lane and Milesi-Ferretti, 2005). This paper assesses if the finding is replicable using alternative data sets, sample periods, and currencies.

\footnotetext{
*Correspondence to: Ron Alquist, Department of Economics, University of Michigan, 611 Tappan St., Ann Arbor, MI 48109, USA.

${ }^{\dagger}$ E-mail: ralquist@umich.edu
} 
Engel and West (2005) argue that one should not expect much exchange rate predictability, given that exchange rate fundamentals are highly persistent and the discount factor is very close to a random walk. We do not dispute this view, especially given the somewhat negative results in Cheung et al.'s $(2005 \mathrm{a}, \mathrm{b})$ comprehensive study of several competing models. ${ }^{2}$ The Cheung et al. study, however, did not deploy the most appropriate test. We remedy the deficiency by using the Clark and West (2006) method. ${ }^{3}$

We summarize the exchange-rate models considered in the exercise in Section 2. Section 3 discusses the data and in-sample fit of the models. Section 4 outlines the forecasting exercise, estimation methods, and the criteria used to compare forecasting performance. The forecasting results are reported in Section 5. Section 6 concludes.

\section{THE MODELS AND SOME EVIDENCE}

We use the random walk model as our benchmark model, in line with previous work. As the workhorse model, we appeal to the Frankel (1979) formulation of the Dornbusch (1976) model as it provides the fundamental intuition for how flexible the exchange rates behave. The sticky price monetary model is

$$
s_{t}=\beta_{0}+\beta_{1} \hat{m}_{t}+\beta_{2} \hat{y}_{t}+\beta_{3} \hat{i}_{t}+\beta_{4} \hat{\pi}_{t}+u_{t}
$$

where $m$ is $\log$ money, $y$ is $\log$ real GDP, $i$ and $\pi$ are the interest and inflation rates, and $u_{t}$ is an error term. The circumflexes denote intercountry differentials. The characteristics of the model are well known. The money stock and the inflation rate coefficients should be positive; and the income and interest rate coefficients negative. The negative coefficient associated with the interest rate coefficient holds as long as prices are sticky; if prices are perfectly flexible, either interest rates or inflation rates should enter in positively.

The specification is more general than it appears. The variables included in (1) encompass the flexible price version of the monetary model, as well as the micro-based general equilibrium models of Stockman (1980) and Lucas (1982). In addition, the sticky price model is an extension of equation (1), where the price variables are replaced by macro variables that capture money demand and overshooting effects. We do not impose coefficient restrictions in equation (1) because theory provides little guidance regarding the values of the parameters.

The next specification we assess is uncovered interest parity (UIP), which states that the expected rate of depreciation is equal to the interest rate differential

$$
s_{t+k}^{e}-s_{t}=\kappa \hat{i}_{t}^{k}
$$

where UIP implies that $\kappa=1$. UIP is not a model per se; rather it is an arbitrage relationship. Testing this form of UIP is a joint test of the theory as well as the rational expectations assumption which, in this context, is often referred to as the unbiasedness hypothesis. One can impose the assumption that UIP holds (that is $\kappa=1$ ), and assess its ability to forecast future movements in the exchange rate. The relationship then amounts to expression

$$
s_{t+k}^{e}-s_{t}=\hat{i}_{t}^{k}
$$

where $\hat{i}_{t}^{k}$ is the interest rate of maturity $k .{ }^{4}$ In contrast to (2), the relationship need not be estimated to generate predictions. We evaluate both forms of the UIP relationship.

The interest rate parity relationship is included in the forecast comparison exercise because it has recently gathered empirical support at long horizons (Chinn and Meredith, 2004), in contrast to the disappointing results at the shorter horizons. Cheung et al. $(2005 \mathrm{a}, \mathrm{b})$ confirm that the long-run interest rates predict exchange rate levels at long horizons better than alternative models. ${ }^{5}$

The third model is based upon Gourinchas-Rey (2005). Gourinchas and Rey log-linearize a transformation of the net exports to net foreign assets variable around its steady-state value. Appealing to the long-run restrictions imposed by assumptions of stationarity of asset to wealth, liability to wealth, and asset-to-liability ratios, they find that either trade flows, portfolio returns, or both, adjust. By way of 


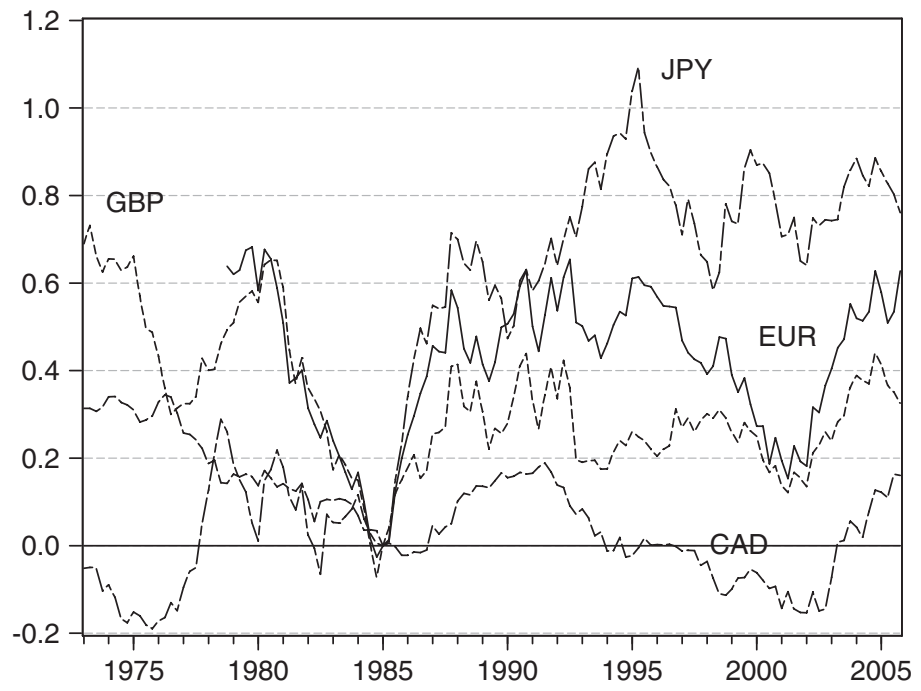

Figure 1. Log exchange rates: 1973-2005 $(1985 q 1=0)$.

contrast, the traditional intertemporal budget approach to the current account takes trade flows as the principal object of interest, because most of the models in this vein contain only one good.

The financial channel implies that the net portfolio return, ret, which combines market and exchange rate-induced valuation effects, exhibits the following relationship:

$$
\operatorname{ret}_{t}=\gamma+\lambda \mathrm{nxa}_{t-1}+Z_{t-1} \Xi+\epsilon_{t}
$$

where $Z$ is a set of control variables, and

$$
\mathrm{nxa}_{t}=\left|\frac{\mu_{m}}{\mu_{x}}\right| \mathrm{xm}_{t}-\left|\frac{\mu_{l}}{\mu_{x}}\right| \mathrm{al}_{t}+\frac{1}{\left|\mu_{x}\right|} \mathrm{xa}_{t}
$$

where the $\mu$ 's are normalized weights; $\mathrm{xm}$ is the log export-to-import ratio; al is the log asset-to-liability ratio; and xa is the log export-to-asset ratio. When one normalizes the exports variable to have a coefficient of unity as in (5), Gourinchas and Rey describe the $n$ xa variable as: 'approximately the percentage increase in exports necessary to restore external balance (i.e. compensate for the deviation from trend of the net exports to net foreign asset ratio).' (2005, p. 12).

They conclude that the financial adjustment channel is quantitatively important at the medium frequency. Asset returns do a fair bit of the adjustment at horizons of up to two years; thereafter, the conventional trade balance channel takes effect. Exchange rates, as part of the financial adjustment process as well as the trade balance process, occupy a dual role. They find that at the one-quarter horizon, $11 \%$ of the variance of exchange rate is predicted, while at one and three years ahead, $44 \%$ and $61 \%$ of the variance are explained. Specifically, they statistically outperform a random walk at all horizons between one and 12 quarters, using the Clark and West (2006) test method. ${ }^{6}$

\section{DATA AND IN-SAMPLE MODEL FIT}

To provide some insight into how plausible the models are, we conduct some regression analysis to show whether the specifications make sense, based on in-sample diagnostics. ${ }^{7}$ 


\subsection{Data}

We rely upon quarterly data for the United States, Canada, UK, and the euro area over the 1970q1$2005 \mathrm{q} 4$ period. $^{8}$ The exchange rate, money, price, and income (real GDP) variables are drawn primarily from the IMF's International Financial Statistics. M1 is used for the money variable, with the exception of the UK, where we use M4. For the money stocks, exchange rates, and interest rates, end-of-quarter, we use the end-of-quarter values. The interest rate data used for the interest rate parity estimates are from the national central banks as well as Chinn and Meredith (2004). The euro area data are drawn from the area wide model, described in Fagan et al. (2001). The end-of-year US foreign asset and liability data are from the Bureau of Economic Analysis (BEA) and interpolated using US quarterly financial account data from IFS.

The measure of external imbalance merits discussion. The central point made by Gourinchas and Rey (2005) and Lane and Milesi-Ferretti (2005) is that the cumulated trade balances can be very inaccurate measures of net foreign asset positions in an era of financial integration, i.e. where gross asset and liability positions are large relative to GDP, and are subject to substantial variation due to exchange rate-induced valuation changes. BEA provides end-of-year data on gross asset and gross liability positions, denominated in dollars. We generate quarterly data by distributing measured financial account balance data over the year. ${ }^{9}$ The Data Appendix contains more detail on exactly how we constructed the time series.

\subsection{Estimation and results}

Using DOLS, we check the monetary model for a long-run relationship between the exchange rate and the explanatory variables (Stock and Watson, 1993)

$$
s_{t}=X_{t} \Gamma+\sum_{i=-2}^{+2} \Delta X_{t+i} B+u_{t}
$$

where $X$ is the vector of explanatory variables associated with the monetary approach.

For the other models, the specifications take on an 'error-correction'-like form. The interest rate parity relationship in (2) implies that the annualized change in the exchange rate equals the interest rate differential of the appropriate maturity. The Gourinchas-Rey specification of equation (3) implies that the exchange rate changes are related to the lagged level of the $n$ xa. In these instances, we implement standard OLS estimates, relying upon heteroskedasticity and serial correlation robust standard errors to conduct inference. ${ }^{10}$

Table 1 displays the estimated cointegrating vectors for the monetary model normalized on the exchange rate. Theory predicts that money enters with a positive coefficient, income with a negative coefficient, and

Table 1. DOLS estimates of the monetary model

\begin{tabular}{lllll}
\hline & EUR & GBP & CAD & JPY \\
\hline Money & -0.154 & -0.224 & 0.029 & 0.422 \\
& $(0.263)$ & $(0.192)$ & $(0.058)$ & $(0.395)$ \\
Output & -1.035 & $-2.696^{*}$ & $-2.938^{* * * *}$ & 1.604 \\
& $(0.899)$ & $(1.567)$ & $(0.512)$ & $(1.181)$ \\
Interest rates & -1.602 & -0.351 & $-2.558^{*}$ & -7.713 \\
Inflation & $(1.495)$ & $(1.441)$ & $(1.419)$ & $(2.393)$ \\
Adj. $R$-sq. & $9.942^{* *}$ & 1.314 & $3.523^{* * *}$ & $(6.080$ \\
Sample & $(4.317)$ & $(1.314)$ & $(1.181)$ & 0.59 \\
$T$ & 0.56 & 0.20 & 0.59 & 80 Q4-05Q2 \\
\hline
\end{tabular}

Notes: Point estimates from DOLS(2,2). Newey-West HAC standard errors in parentheses. ${ }^{*},{ }^{* *},{ }^{* * *}$ Indicate statistical significance at the $10 \%, 5 \%, 1 \%$ level. 
Table 2. Interest rate parity regressions

\begin{tabular}{|c|c|c|c|c|c|}
\hline & EUR & EUR & GBP & CAD & JPY \\
\hline 3-month & $\begin{array}{l}-6.247^{* * * *} \\
(3.376)\end{array}$ & $\begin{array}{l}-0.678 \\
(1.645)\end{array}$ & $\begin{array}{l}-1.632^{* * *} \\
(0.980)\end{array}$ & $\begin{array}{l}-0.669^{* * * *} \\
(0.487)\end{array}$ & $\begin{array}{l}-2.386^{* * *} \\
(0.966)\end{array}$ \\
\hline Adj. $R$-sq. & 0.07 & -0.01 & 0.04 & 0.00 & 0.04 \\
\hline Sample & $99 \mathrm{Q} 2-05 \mathrm{Q} 4$ & $90 \mathrm{Q} 4-05 \mathrm{Q} 4$ & $75 \mathrm{Q} 2-05 \mathrm{Q} 4$ & $75 \mathrm{Q} 2-05 \mathrm{Q} 4$ & 75Q1-05Q4 \\
\hline$T$ & 27 & 64 & 123 & 124 & 124 \\
\hline 1-year & - & - & $\begin{array}{l}-0.759^{* * *} \\
(0.873)\end{array}$ & $\begin{array}{l}-0.675^{* * * *} \\
(0.545)\end{array}$ & $\begin{array}{l}-2.615^{* * * *} \\
(1.370)\end{array}$ \\
\hline Adj. $R$-sq. & - & - & 0.01 & 0.02 & 0.11 \\
\hline Sample & - & - & 76Q1-05Q4 & 75Q1-05Q4 & 97Q4-05Q4 \\
\hline$T$ & - & - & 115 & 120 & 33 \\
\hline 5 -year & - & $\begin{array}{l}1.566 \\
(0.332)\end{array}$ & $\begin{array}{l}0.616 \\
(0.363)\end{array}$ & $\begin{array}{l}1.277 \\
(0.360)\end{array}$ & $\begin{array}{l}0.225 \\
(0.479)\end{array}$ \\
\hline Adj. $R$-sq. & - & 0.33 & 0.04 & 0.10 & -0.01 \\
\hline Sample & - & 83Q4-05Q4 & 80Q1-05Q4 & 80Q1-05Q4 & $80 \mathrm{Q} 2-05 \mathrm{Q} 4$ \\
\hline$T$ & - & 64 & 104 & 100 & 83 \\
\hline
\end{tabular}

Notes: Point estimates from OLS. Newey-West HAC standard errors, assuming lag order $2(k-1)$, in parentheses. *, ***,*** indicate statistically different from unity at the $10 \%, 5 \%, 1 \%$ level.

inflation with a positive coefficient. Interest rates have a negative independent effect above and beyond that of inflation if prices are sticky, so that higher nominal interest rates, holding inflation constant, appreciate the home currency.

As usual, the estimated money coefficients are wrongly signed and are insignificant. Money has the right sign for Canada and Japan, but the values of the coefficients are substantially smaller than suggested by theory, and are not statistically significant. All other coefficients typically have the expected sign. Hence, we have some slight evidence in favour of a long-run cointegrating relationship between monetary fundamentals and nominal exchange rates in the three cases.

The interest rate parity results in Table 2 replicate those found in Chinn and Meredith (2004): at short horizons, the coefficient on interest rates points in a direction inconsistent with the joint null hypothesis of UIP and unbiased expectations. The significance levels in this panel are for the null of the slope coefficient equalling unity.

For the euro-dollar rate, we report results for a sample that pertains to the post-EMU sample, and a longer one (back to 1990) relying upon the synthetic euro, and using the German three-month rate as a proxy for the euro interest rate. In both cases, the three-month forward discount points to the wrong direction, on average, with the bias more pronounced in the shorter post-EMU period.

At the long horizon of 5 years, interest rates point to the right direction, and the null of a unitary coefficient cannot be rejected at conventional levels. This pattern of results matches that reported in Cheung et al. (2005b), as well as Chinn and Meredith (2004). While the results are promising, the adjusted $R^{2}$ 's are quite low, suggesting that the interest rate differential is a poor predictor of changes in the exchange rate.

Finally, we turn to the regression with our measure of external imbalance. The series we have generated using BEA data is plotted in Figure 2. We cannot exactly replicate the patterns in the Gourinchas-Rey series, although the broad patterns of our series are consistent with theirs.

Theory predicts that the exchange rate depreciates in response to a negative value of the explanatory variable. Given the way in which the exchange rate is defined, this implies a negative sign. Table 3 reports some positive results, in that the coefficients are statistically significant in the right direction 10 out of 12 times.

In addition, the effect appears more pronounced at the short and short to intermediate horizon (three months, 1 year) than at 5 years. In addition, the adjusted $R^{2}$ s for these regressions are fairly high by comparison with the long horizon interest rate regressions. These results augur well for positive results on the forecasting end. 


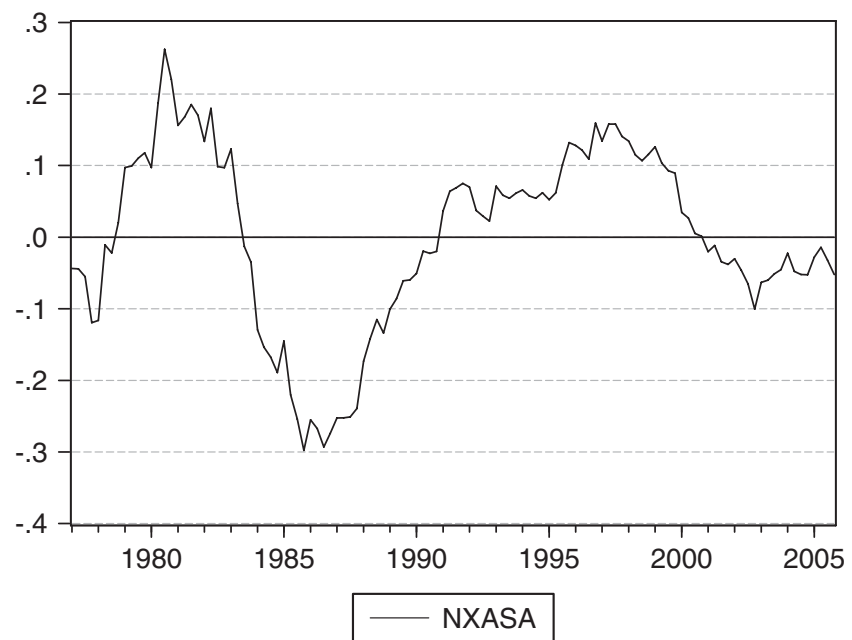

Figure 2. The measure of external imbalance. Sources: Bureau of Economic Analysis, International Financial Statistics, and authors' calculations.

Table 3. Measure of external imbalance

\begin{tabular}{|c|c|c|c|c|}
\hline & EUR & GBP & CAD & JPY \\
\hline 3-month & $\begin{array}{l}-0.530 \text { **** } \\
(0.159)\end{array}$ & $\begin{array}{l}-0.287^{* * *} \\
(0.142)\end{array}$ & $\begin{array}{l}-0.142^{* *} \\
(0.071)\end{array}$ & $\begin{array}{l}-0.436^{* *} \\
(0.190)\end{array}$ \\
\hline Adj. $R$-sq. & 0.08 & 0.04 & 0.02 & 0.04 \\
\hline Sample & 79Q1-05Q4 & 76Q2-05Q4 & 76Q2-05Q4 & 76Q2-05Q4 \\
\hline$T$ & 108 & 119 & 119 & 119 \\
\hline 1-year & $\begin{array}{l}-0.532^{\text {**** }} \\
(0.137)\end{array}$ & $\begin{array}{l}-0.373^{\text {***** }} \\
(0.110)\end{array}$ & $\begin{array}{l}-0.169 \\
(0.055)\end{array}$ & $\begin{array}{l}-0.381^{* *} \\
(0.150)\end{array}$ \\
\hline Adj. $R$-sq. & 0.28 & 0.18 & 0.13 & 0.12 \\
\hline Sample & 79Q4-05Q4 & 77Q1-05Q4 & 77Q1-05Q4 & 77Q1-05Q4 \\
\hline$T$ & 105 & 116 & 116 & 116 \\
\hline 5 -year & $\begin{array}{l}-0.266^{\text {***** }} \\
(0.058)\end{array}$ & $\begin{array}{l}-0.143^{\text {***** }} \\
(0.053)\end{array}$ & $\begin{array}{l}-0.091^{\text {**** }} \\
(0.027)\end{array}$ & $\begin{array}{l}-0.108^{*} \\
(0.059)\end{array}$ \\
\hline Adj. $R$-sq. & 0.30 & 0.20 & 0.21 & 0.08 \\
\hline Sample & 83Q4-05Q4 & 81Q1-05Q4 & 81Q1-05Q4 & 81Q1-05Q4 \\
\hline$T$ & 89 & 100 & 100 & 100 \\
\hline
\end{tabular}

Notes: Point estimates from $\operatorname{DOLS}(2,2)$. Newey-West HAC standard errors in parentheses. ${ }^{*}{ }^{* *},{ }^{*} * * *$ indicate statistical significance at the $10 \%, 5 \%, 1 \%$ level.

\section{FORECASTING PROCEDURE AND COMPARISON}

\subsection{The forecasting exercise}

To ensure that the conclusions are not sensitive to the choice of a specific out-of-forecasting period, we use two out-of-sample periods to assess model performance: 1987q2-2005q4 and 1999q1-2005q4. The former period conforms to the post-Louvre Accord period, while the latter spans the post-EMU period. The longer out-of-sample period (1987-2005) spans a period of relative dollar stability with one upswing and downswing in the dollar's value. 
We adopt the convention in empirical exchange rate modelling of implementing rolling regressions established by Meese and Rogoff (1983). We estimate the model for a given sample, use the parameter estimates to generate out-of-sample forecasts, roll the sample forward one observation, and repeat the procedure. We continue until we exhaust all of the out-of-sample observations. While rolling regressions do not incorporate possible efficiency gains as the sample moves forward through time, the procedure alleviates parameter instability, which is common in exchange rate modelling.

We use an error correction specification for the sticky price monetary model, while the competing models intrinsically possess an error correction nature. In the monetary model, both the exchange rate and its economic determinants are $I(1)$. The error correction specification allows for the long-run interaction effect of these variables, captured by the error correction term, in generating forecasts. If the variables are cointegrated, then the former specification is more efficient that the latter one and is expected to forecast better in long horizons. If the variables are not cointegrated, the error correction specification leads to spurious results. Because we detect evidence in favour of cointegration, we rely upon error correction specifications for the monetary model.

The general expression for the relationship between the exchange rate and fundamentals is

$$
s_{t}=X_{t} \Gamma+\epsilon_{t}
$$

where $X_{t}$ is a vector of fundamental variables indicated in (1). The error correction estimation is a two-step procedure. In the first step, we identify the long-run cointegrating relation implied by (7) using DOLS. Next we incorporate the estimated cointegrating vector $(\tilde{\Gamma})$ into the error correction term, and estimate the resulting equation

$$
s_{t}-s_{t-k}=\delta_{0}+\delta_{1}\left(s_{t-k}-X_{t-k} \widetilde{\Gamma}\right)+u_{t}
$$

using OLS. Equation (8) is an error-correction model stripped of short-run dynamics. Mark (1995) and Chinn and Meese (1995) use a similar approach, except that they impose the cointegrating vector a priori. The specification is motivated by the difficulty in estimating the short-run dynamics in exchange rate equations. ${ }^{11}$ In contrast to other studies, our estimates of the cointegrating relationship vary as the data window moves. ${ }^{12}$

\subsection{Forecast comparison}

To evaluate the forecasting accuracy of the different structural models, we use the adjusted MSPE statistic proposed by Clark and West (2006). Under the null hypothesis, the MSPE of a zero mean process is the same as the MSPE of the linear alternative. Despite the equality, one expects the alternative model's sample MSPE to be larger than the null's. To adjust for the downward bias, Clark and West propose a procedure that performs well in simulations.

We calculate the test statistic as the difference between the MSPE of the random walk model and the MSPE from the linear alternative, which is then adjusted downward to account for the spurious in-sample fit. Under the first model, the process is a zero mean martingale difference process; under the second model, the process is linear,

$$
\begin{aligned}
& \text { Model 1: } y_{t+1}=e_{t+1} \\
& \text { Model 2: } y_{t+1}=X_{t+1} B+e_{t+1}, E\left(e_{t+1} \mid I_{t}\right)=0
\end{aligned}
$$

Our inferences are based on a formal test for the null hypothesis of no difference in the accuracy, as measured by the MSPE, of the two competing forecasts, the linear (structural) model and the driftless random walk. Thus, the hypothesis test is

$$
\begin{aligned}
& H_{0}: \sigma_{1}^{2}-\sigma_{2}^{2}=0 \\
& H_{A}: \sigma_{1}^{2}-\sigma_{2}^{2}>0
\end{aligned}
$$

A value larger (smaller) than zero indicates that the linear model (random walk) outperforms the random walk (linear model). The difference between the two MSPEs is asymptotically normally distributed. ${ }^{13}$ For 
forecast horizons beyond one period, one needs to account for the autocorrelation induced by the rolling regression. We use Clark and West's proposed estimator for the asymptotic variance of the adjusted mean between the two MSPEs, which is robust to the serial correlation.

\section{COMPARING THE FORECASTS}

Tables 4 and 5 present the results of comparing the forecasts. The top entry in each cell is the difference in the MSPEs (positive entries denote outperformance relative to a random walk). The Clark-West statistic is displayed below (Diebold-Mariano-West statistic for the interest rate parity results); this can be read as a $z$-statistic.

At most horizons, the interest rate parity model does about as well as the random walk. ${ }^{14}$ It tends to do better at longer horizons, but it only outperforms the random walk for the pound at the one-quarter horizon during the second period. Imposing the unit coefficient worsens the forecast, although forecasts based on the arbitrage relationship do well relative to the random walk for the euro. Among the nine statistically significant outcomes that suggest that the random walk outperforms the linear alternative, five are based on the UIP model with the unit coefficient imposed (all at the shorter horizons).

Interestingly, we do not find that the estimated UIP works particularly well. For the Canadian dollar, which Clark and West found could be well predicted by interest rate fundamentals over the 1990m01$2003 \mathrm{~m} 10$ period, we find only slight and insignificant outperformance over the $1987 \mathrm{q} 2-05 \mathrm{q} 4$ period. Of course, the results can well differ due to the different sample periods and horizons, and perhaps most importantly the number of observations available in the out-of-sample periods because the dispersion of the test distribution decreases as this number increases. We do find outperformance of the random walk in the case of the UK pound, something that Clark and West did not detect.

Table 4. MSPE difference and $z$-score for Clark-West test

\begin{tabular}{|c|c|c|c|c|c|c|c|c|c|}
\hline & & (1) & (2) & (3) & (4) & $(5)$ & (6) & (7) & (8) \\
\hline & & \multicolumn{4}{|c|}{ 1987Q2-2005Q4 } & \multicolumn{4}{|c|}{ 1999Q1-2005Q4 } \\
\hline & Horizon & EIRP & IRP & S-P & NXA & Est. IRP & IRP & S-P & NXA \\
\hline Panel A: CAD/USD & & & & & & & & & \\
\hline & $\begin{array}{l}1 \\
4 \\
20\end{array}$ & $\begin{array}{r}0.05 \\
0.80 \\
-0.02 \\
-0.36 \\
0.06 \\
0.23\end{array}$ & $\begin{array}{r}-0.12 \\
-0.33 \\
-0.08 \\
-2.44 \\
0.02 \\
2.53\end{array}$ & $\begin{array}{r}-0.06 \\
-0.66 \\
-0.11 \\
-1.62 \\
0.00 \\
0.03\end{array}$ & $\begin{array}{r}-0.10 \\
-1.71 \\
-0.12 \\
-0.54 \\
0.02 \\
0.10\end{array}$ & $\begin{array}{c}-0.09 \\
-0.83 \\
-0.12 \\
-2.80 \\
-0.04 \\
-\end{array}$ & $\begin{array}{r}-0.12 \\
-0.33 \\
-0.11 \\
-2.57 \\
0.00 \\
0.85\end{array}$ & $\begin{array}{r}-0.10 \\
-0.95 \\
0.08 \\
0.47 \\
-0.01 \\
-\end{array}$ & $\begin{array}{r}0.07 \\
1.71 \\
0.08 \\
0.54 \\
-0.05 \\
-\end{array}$ \\
\hline Panel B: GBP/USD & $\begin{array}{l}1 \\
4 \\
20\end{array}$ & $\begin{array}{r}-0.25 \\
-0.82 \\
-0.19 \\
-0.78 \\
0.04 \\
0.18\end{array}$ & $\begin{array}{r}-0.25 \\
-0.16 \\
-0.11 \\
-1.62 \\
0.00 \\
0.28\end{array}$ & $\begin{array}{l}0.29 \\
0.63 \\
0.13 \\
0.34 \\
0.00 \\
0.03\end{array}$ & $\begin{array}{r}-0.06 \\
0.15 \\
0.02 \\
0.04 \\
0.05 \\
0.35\end{array}$ & $\begin{array}{r}0.25 \\
1.73 \\
0.04 \\
0.29 \\
-0.05 \\
-\end{array}$ & $\begin{array}{c}-0.20 \\
-0.32 \\
-0.18 \\
-3.81 \\
0.01 \\
-\end{array}$ & $\begin{array}{r}0.37 \\
1.76 \\
0.24 \\
0.30 \\
-0.04 \\
-\end{array}$ & $\begin{array}{r}0.07 \\
0.85 \\
0.19 \\
0.65 \\
-0.02 \\
-\end{array}$ \\
\hline
\end{tabular}

Notes: EIRP: estimated interest parity model; IRP: interest parity model; S-P: sticky price monetary model; NXA: transformed net exports model. The top entry is the Clark-West test statistic times 100. A positive value indicates that the MSPE of the linear alternative is smaller than the MSPE of the random walk model. The entry underneath is the $z$-score for the null hypothesis of no difference between the random walk and the linear alternative. For the interest rate parity forecasts, the $z$-score is the Diebold-Mariano (1995) and West (1996) test statistic. The $z$-score for the 20-quarter ahead forecasts is omitted because the Clark-West procedure requires the forecast sample to be greater than two times the forecast horizon to compute the robust standard error. 
Table 5. MSPE difference and $z$-score for Clark-West test

\begin{tabular}{|c|c|c|c|c|c|c|c|c|c|}
\hline & & (1) & (2) & (3) & (4) & (5) & (6) & (7) & (8) \\
\hline & \multicolumn{5}{|c|}{ 1987Q2-2005Q4 } & \multicolumn{4}{|c|}{ 1999Q1-2005Q4 } \\
\hline & Horizon & EIRP & IRP & S-P & NXA & Est. IRP & IRP & S-P & NXA \\
\hline \multicolumn{10}{|l|}{ Panel C: EUR/USD } \\
\hline & 1 & -0.45 & -0.14 & - & -0.23 & -0.02 & -0.25 & -0.50 & 0.80 \\
\hline & & -2.16 & -0.12 & - & -0.48 & -0.15 & -0.40 & -1.09 & 1.99 \\
\hline & 4 & - & - & - & -0.22 & - & - & -0.35 & 0.66 \\
\hline & & - & - & - & -0.34 & - & - & -1.05 & 1.17 \\
\hline & 20 & 0.04 & 0.01 & - & -0.09 & -0.02 & 0.09 & 0.06 & -0.03 \\
\hline & & 0.07 & 0.91 & 一 & -0.83 & 一 & 一 & 一 & 一 \\
\hline \multicolumn{10}{|l|}{ Panel D: JPY/USD } \\
\hline & 1 & 0.64 & -0.01 & 0.32 & -0.21 & 0.40 & -0.15 & 0.02 & -0.15 \\
\hline & & 1.55 & -0.05 & 0.57 & -0.47 & 1.01 & -0.10 & 0.06 & -0.38 \\
\hline & 4 & - & -0.23 & 0.76 & -0.13 & 1.22 & -0.23 & -0.29 & -0.08 \\
\hline & & - & -2.41 & 1.09 & -0.32 & 1.38 & -1.37 & -0.56 & -0.12 \\
\hline & 20 & -0.03 & -0.08 & 0.00 & 0.13 & 0.13 & -0.20 & 0.00 & 0.03 \\
\hline & & -0.06 & -0.10 & 0.00 & 0.12 & - & - & - & - \\
\hline
\end{tabular}

Notes: EIRP: estimated interest parity model; IRP: interest parity model; S-P: sticky price monetary model; NXA: transformed net exports model. The top entry is the Clark-West test statistic times 100. A positive value indicates that the MSPE of the linear alternative is smaller than the MSPE of the random walk model. The entry underneath is the $z$-score for the null hypothesis of no difference between the random walk and the linear alternative. For the interest rate parity forecasts, the $z$-score is the Diebold-Mariano (1995) and West (1996) test statistic. The $z$-score for the 20-quarter ahead forecasts is omitted because the Clark-West procedure requires the forecast sample to be greater than two times the forecast horizon to compute the robust standard error.

The sticky price monetary model outperforms the random walk in one-quarter ahead forecasts during 1999q1-2005q4 for the pound, but performs only as well as, or significantly worse than, the random walk for the other countries. The finding is consistent with Cheung et al. (2005a, b), who point out that the papers in which the sticky-price monetary model outperforms the random walk in out-of-sample forecasts usually involve a cointegrating vector estimated over the entire sample, as in MacDonald and Taylor (1994). Our test is more stringent. We estimate the cointegrating vector over a rolling window rather than the entire sample, making the forecasts true ex ante predictions.

We find favourable support for the use of the measure of external imbalance, particularly when we estimate the weights in the $n$ xa variable over the longer sample. In the second subsample, it outperforms the random walk at short horizons for the Canadian dollar and the euro at the 5\% significance level. The results are less favourable at long horizons and not particularly positive for the yen.

Both of these patterns are consistent with those identified by in Gourinchas and Rey (2005), although our findings are weaker than theirs. Indeed, they found that the lagged measure of external imbalance outperforms the random walk at both short and long horizons.

Although our method mimics theirs, there are plausible reasons for the discrepancies. First, the Gourinchas and Rey data are not publicly available; hence, we constructed our own measure of $n$ xa that approximates theirs. A second related reason is that Gourinchas and Rey have a time series extending back to the 1950s, which enables them to estimate precisely the weights in the $n$ xa variable with a sample of 105 quarterly observations. Indeed, Gourinchas and Rey state that they need the long estimation window to obtain stable estimates of the cointegrating vector (Gourinchas and Rey, 2005). By way of contrast, our $n$ xa measure begins in $1977 \mathrm{q} 1$, giving us an estimation window of 41 observations for the first subsample (1977q1-1987q1) and 88 for the second subsample (1977q1-1998q4). Thus, the differences are likely due to the alternative samples. In fact, the difference in the MSPEs is positive, if not statistically significant, in the sample with 88 observations, suggesting that forecasts based on a longer time series may perform better for bilateral exchange rates. 
This finding is surprising, because the principal prediction of the Gourinchas-Rey approach pertains to multilateral exchange rate returns rather than to bilateral exchange rates. According to the model, one should not expect the measure of external imbalance to have predictive power for currencies with modest valuation effects, such as the Canadian dollar. To the extent that the variable has predictive power for bilateral rates, the Gourinchas-Rey model may have broader implications for empirical exchange rate modelling.

Finally, although their model outperforms a random for the other currencies, no model forecasts the yen particularly well. There is no clear explanation for the outcome, and the results merit further investigation.

Overall, using appropriate test statistics yields the finding that in nine out of 72 cases significantly worse performance is recorded by the model-based prediction, while in five cases, significantly better performance is obtained (using a 10\% marginal significance level). In both instances, the number of rejections of the null of no outprediction is greater than what would be expected to occur randomly.

\section{CONCLUSION}

We find evidence in support of a new model of exchange rate modelling, motivated by intertemporal budget constraints, and contrast it with the results based upon interest rate parity and the sticky price monetary model. The evidence suggests that one can forecast changes in the spot rate using Gourinchas and Rey's $n$ xa measure at short horizons. The monetary model does not do well against the random walk, even though we rely upon a procedure for the testing of statistical significance that has better size characteristics than the Diebold-Mariano-West test. Finally, we level the approaches against a new currency, the euro. In this regard, we rely upon both actual data post-EMU and synthetic data that begin earlier.

We cannot identify a model that reliably outperforms a random walk model despite the use of an improved test. On the other hand, this better-sized test forwarded by Clark and West indicates that the outof-sample performance of structural models is not as poor as has been suggested by earlier statistical tests. There is evidence that forecasts based on the economic models can outperform the random walk at short horizons. In addition, the euro-dollar exchange rate-both its synthetic actual version-shares many of the same attributes that the deutschemark-dollar rate exhibited in terms of predictability and relevant determinants. The model that relies upon a log-linearized version of net exports variable does not do badly compared with the other models. However, perhaps for reasons related to data and sample differences, we are unable to replicate exactly the very strong out-of-sample performance that Gourinchas and Rey documented.

\section{ACKNOWLEDGEMENTS}

We thank Ken West, Paul De Grauwe, Nelson Mark, Helene Rey, and the participants at a Federal Reserve Board seminar, the ECB-Bank of Canada workshop 'Exchange Rate Determinants and Economic Impacts' and the HKIMR conference on 'International Financial Markets and the Macroeconomy' for helpful comments. We also thank Gian Maria Milesi-Ferretti for providing data on foreign assets and liabilities. The European Union Center at the University of Michigan generously provided financial support. The views contained in the paper are solely those of the authors and do not necessarily represent those of the institutions the authors are associated with, the Bank of Canada, the ECB, or the HKIMR.

\section{APPENDIX A: DATA APPENDIX}

Unless otherwise stated, we use seasonally adjusted quarterly data from the IMF International Financial Statistics ranging from the second quarter of 1973 to the last quarter of 2005. The exchange rate data are 
end-of-period exchange rates. The output data are measured in constant 2000 prices. The consumer price indexes also use 2000 as base year. Inflation rates are calculated as four-quarter log differences of the CPI.

Canadian M1 and UK M4 are drawn from IFS. The US M1 is drawn from the Federal Reserve Bank of St. Louis's FRED II system. The euro area M1 is drawn from the ECB's area wide macroeconomic (AWM) model described in Fagan et al. (2001), located on the euro area business cycle network website (http:// www.eaben.org/data/awm/index.htm).

The overnight interest rates are from the respective central banks. The three-month, annual, and five-year interest rates are end-of-period constant maturity interest rates from the national central banks. For Canada and the United Kingdom, we extend the interest rate time series using data from IMF country desks. See Chinn and Meredith (2004) for details. We use German interest rate data from the Bundesbank to extend the euro area interest rates.

The annual foreign asset and liability data are from the BEA website (http://www.bea.gov/bea/di/home/ iip.htm). The quarterly data are interpolated by cumulating financial account flows from IFS and forcing the cumulative sum to equal the year-end value from the BEA. The quarterly positions grow at the rate given by the financial account data in IFS, subject to the constraint that the year-end value equals the official BEA data.

To construct the measure of external imbalance, we backed out the weights implied by the point estimates on page 13 of Gourinchas and Rey using the estimates from the DOLS regressions on page 12. The procedure assumes that the weights are constant across subsamples. The problem reduces to solving three equations in three unknowns, where the unknowns were the weights normalized on $\mu_{x}$. The weights are

$$
\mu_{x} /\left(\mu_{x}+1\right)=1.09639, \quad \mu_{l} /\left(\mu_{x}+1\right)=0.72308 \text { and } 1 /\left(\mu_{x}+1\right)=-0.09294
$$

\section{NOTES}

1. The evaluation procedure also differs slightly from that in Cheung et al. (2005a, b). We evaluate the mean-squared prediction error (MSPE) of the forecasted change in the exchange rate rather than the level. In the context of the error correction forecasts we make, and conditioning on the current spot exchange rate, the resulting comparison is the same; to remain close to the spirit of the Clark and West (2006) paper, however, we retain the comparison in changes.

2. See Faust et al. (2003), while MacDonald and Marsh (1999), Groen (2000), and Mark and Sul (2001) provide more positive results.

3. Other papers using the Clark-West approach include Gourinchas and Rey (2005) and Molodtsova and Papell (mimeo, 2006).

4. For notational consistency, we use the log approximation in discussing interest rate parity, but we also use the exact expression in the regressions and the forecasting exercises. The results do differ somewhat between the two methods, particularly when the sample includes the 1970s when interest rates were relatively high.

5. Despite the finding, there is little evidence that long-term interest rate differentials - or, equivalently, long-dated forward rates-have been used for forecasting at the horizons we are investigating. One exception from the non-academic literature is Rosenberg (2001).

6. They use an initial estimation window of 1952q1-1978q1, and roll the regressions for the cointegrating vector.

7. For a discussion on why one might want to rely solely on in-sample diagnostics, see Inoue and Kilian (2004).

8. Data series for the euro area begin around 1980 .

9. In the previous version of this paper, we used the Lane and Milesi-Ferretti (mimeo, 2004) data.

10. For the $n$ xa regressions, we follow the suggestion of Newey and West and set the truncation lag equal to $4(T / 100)^{2 / 9}$. In the interest rate parity regressions, where under the unbiasedness null the errors follow an $\mathrm{MA}(k-1)$ process, we use a truncation lag of $2(k-1)$ indicated by Cochrane (1991).

11. We exclude short-run dynamics in equation (8) for two reasons. The first is that the use of equation (8) yields true ex ante forecasts and makes our exercise directly comparable with, for example, Mark (1995), Chinn and Meese (1995), and Groen (2000). Second, the inclusion of short-run dynamics creates additional demands on the generation of the right-hand side variables and the stability of the short-run dynamics that complicate the forecast comparison exercise beyond a manageable level.

12. We do not impose restrictions on the $\beta$-parameters in (1) because we do not have strong priors on the exact values of the coefficients.

13. Since the interest rate parity coefficient of unity is imposed, rather than estimated, we used the Diebold-Mariano (1995) and West (1996) test statistic, assuming that the $k$-step ahead forecast error follows an MA $(k-1)$ process.

14. As opposed to using the interest differentials as fundamentals as in Clark and West (2006) and Molodtsova and Papell (mimeo, 2006), we use the exact formula implicit in the unbiasedness hypothesis. 


\section{REFERENCES}

Cheung Y-W, Chinn M, Garcia Pascual A. 2005a. Empirical exchange rate models of the nineties: are any fit to survive? Journal of International Money and Finance 24 (November): 1150-1175.

Cheung Y-W, Chinn M, Garcia Pascual A. 2005b. 'Recent exchange rate models: in-sample fit and out-of-sample performance.' In Exchange Rate Modelling: Where Do We Stand? DeGrauwe P (ed). MIT Press: Cambridge.

Chinn M, Alquist R. 2000. Tracking the euro's progress. International Finance 3(3): 357-374.

Chinn M, Meese R. 1995. Banking on currency forecasts: how predictable is change in money? Journal of International Economics 38: $161-178$.

Chinn M, Meredith G. 2004. Monetary policy and long horizon uncovered interest parity. IMF Staff Papers 51(3): 409-430.

Clark TE, West KD. 2006. Using out-of-sample mean squared prediction errors to test the martingale difference hypothesis. Journal of Econometrics 135(1-2): 155-186.

Cochrane J. 1991. Production-based asset pricing and the link between stock returns and economic fluctuations. Journal of Finance 46(March): 207-234.

Dornbusch R. 1976. Expectations and exchange rate dynamics. Journal of Political Economy 84: 1161-1176.

Diebold FX, Mariano R. 1995. Comparing predictive accuracy. Journal of Business and Economic Statistics 13: $253-265$.

Engel C, West KD. 2005. Exchange rates and fundamentals. Journal of Political Economy 113(2): 485-517.

Fagan G, Henry J, Mestre R. 2001. An area-wide model (AWM) for the euro area. ECB Working Paper No. 42.

Faust J, Rogers J, Wright J. 2003. Exchange rate forecasting: the errors we've really made. Journal of International Economics 60: 35-60.

Frankel JA. 1979. On the mark: a theory of floating exchange rates based on real interest differentials. American Economic Review 69: $610-622$.

Gourinchas P-O, Rey H. 2005. International financial adjustment. NBER Working Paper No. 11155.

Groen JJJ. 2000. The monetary exchange rate model as a long-run phenomenon. Journal of International Economics 52: $299-320$.

Heaney D, Pattenden K. 2005. Change in unconditional foreign exchange rate volatility: an analysis of the GBP and USD price of the Euro from 2002 to 2003. Applied Economics Letters 12(15): 929-932.

Inoue A, Kilian L. 2004. In-sample or out-of-sample tests of predictability: which one should we use? Econometric Review 23(4): $371-402$.

Lane P, Milesi-Ferretti GM. Forthcoming. The external wealth of nations mark II; Revised and extended estimates of foreign assets and liabilities 1970-2004. Journal of International Economics.

Lucas R. 1982. Interest rates and currency prices in a two-country world. Journal of Monetary Economics 10: 335-359.

MacDonald R, Marsh I. 1999. Exchange Rate Modeling. Kluwer: Boston.

MacDonald R, Taylor MP. 1994. The monetary model of the exchange rate: long-run relationships, short-run dynamics, and how to beat a random walk. Journal of International Money and Finance 13: 276-290.

Mark N. 1995. Exchange rates and fundamentals: evidence on long horizon predictability. American Economic Review 85: 201-218.

Mark N, Sul D. 2001. Nominal exchange rates and monetary fundamentals: evidence from a small post-Bretton Woods panel. Journal of International Economics 53: 29-52.

Meese R, Rogoff K. 1983. Empirical exchange rate models of the seventies: do they fit out of sample? Journal of International Economics 14: 3-24.

Mussa M. 2005. The euro, the dollar, and the international monetary system. Journal of Policy Modeling 27(4): 445-454.

Nautz D, Offermanns C. 2006. Does the euro follow the German mark? Evidence from the monetary model of the exchange rate. European Economic Review 50(5): 1279-1295.

Papell DH, Molodtsova T. 2007. Out-of-sample exchange rate predictability with Taylor rule fundamentals. Mimeo.

Rosenberg M. 2001. Investment Strategies based on Long-Dated Forward Rate/PPP Divergence. FX Weekly. Deutsche Bank Global Markets Research: New York.

Schnatz B, Vijselaar F, Osbat C. 2004. Productivity and the euro-dollar exchange rate. Review of World Economics 140(1): 1-30.

Stock JH, Watson MW. 1993. A simple estimator of cointegrating vectors in higher order integrated systems. Econometrica 61(4): $783-820$.

Stockman A. 1980. A theory of exchange rate determination. Journal of Political Economy 88: 673-698.

West KD. 1996. Asymptotic inference about predictive ability. Econometrica 64: 1067-1084. 